\title{
Striking an Interactive Balance Between Nature and Culture in Human Developmental Exploits for Sustainable Environmental Protection and Management
}

\author{
George Ohabuenyi $\mathrm{Abah}^{1} \&$ Sebastian Okechukwu Onah ${ }^{2}$ \\ ${ }^{1}$ Department of Philosophy, University of Nigeria, Nsukka, Nigeria \\ ${ }^{2}$ Department of Sociology \& Anthropology, University of Nigeria, Nsukka, Nigeria \\ Correspondence: Sebastian Okechukwu Onah, Department of Sociology \& Anthropology, University of Nigeria, \\ Nsukka, Nigeria.
}

Received: January 30, 2020 Accepted: April 15, 2020 Online Published: April 30, 2020

doi:10.5539/gjhs.v12n5p110 URL: https://doi.org/10.5539/gjhs.v12n5p110

\begin{abstract}
Background: The desacralization of nature, the resultant effect of which is evident in multiple environmental issues, has become a global concern. The subtle, yet insidious poisoning of the food-chain, the chemical burdening of the nature cycle, the increasing volume of air pollution, the greenhouse effect with the attendant global warming, climate change, flash floods, and so on, are the echoes of the murderous attacks on nature. At the centre of this destruction is the human species, whose unguarded actions against nature especially in his violent movements from the biosphere to the technosphere, stifles the ecosystemic homeostasis. Yet, development demands that man must necessarily move from nature to culture wherein the destruction of nature is inevitable.
\end{abstract}

Methodology: The study used a qualitative design. The methods used were historical, descriptive, and critical. The historical method was used to trace the submissions of varied literatures on nature-culture relationships.

Results: Using the qualitative research design, thereby applying the historical, descriptive and evaluative methodological approaches, and reclining on the Risk Society Theory of Ulrich Beck as well as the Ecological Modernisation Theory of Arthur J.P Mol, we would like to establish that the attainment of sustainable environmental protection and management in the society would largely depend on the maintenance of a respectful balance between cultural superimpositions and natural landscapes in the contemporary society.

Recommendation: It is recommended that all developmental projects must be subjected to, and pass through environmental protection and sustainability censorship and tests. This will help to create reasonable and reconciliatory boundaries between nature and culture for a balanced human environment.

Keywords: biosphere, cultural superimpositions, ecosystemic homeostasis, sustainability censorship, technosphere

\section{Introduction}

It is a common experience in our present age that there are changes in the climate the effects of which are replete in human environment. These changes not only suggest a violent interference with the biosphere, but in a great deal project remotely, the destruction of human existence. Unfortunately, humans contribute a great deal in fixing these changes through undue exploitations of nature. These exploitations are generated in human attempts to move from nature to culture in the name of development. As far as humans lived only by hunting and gathering, their needs were satisfied by the resources which nature spontaneously offered, and their impact on nature was therefore negligible. Things changed when humans actively began to intervene in natural cycles through agriculture and breeding, which represented the first major form of transformation of the natural environment. For a long time, this did not cause any significant negative consequences for humans, also because of limited population growth.

Nevertheless, the advancement in technology which accompanied the scientific revolution considerably increased productive potential causing in some areas a greater availability of commodities and thus a qualitative and quantitative improvement of human life. However, this also led to a chain reaction replete in an intense and often irrational exploitation of the land, resulting in rapid and profound changes in the environment and the progressive spread and increase of pollution. Invariably, this has degenerated to a culture "which considers man as a mere 
production tool and consumer subject" (Blasi \& Zamagni, 1991). Thus today, people are faced with increasingly serious problems, as they realize that they are also part of the environment and that uncontrolled changes in it could lead to the extinction of the human race. As a follow-up, warnings from ecological experts, Earth Summits, Environmental Conferences abound, signaling that natural hazards in the likes of global warming, pollution, flash floods etc may, in no distant time, overtake our 'Common Home'(Francis, 2015) with an irredeemable destruction if we do not tender our environment carefully. The tension created by these warnings, the experiences of the changes in weather, and the destruction of homes and properties by some of the natural hazards, have led humans into a ceaseless inquiry for the best method to forestall the damaging effects of these hazards. This gave rise to so many schools of thought that hanker after environmental sustainability with varied theories.

Hence, the principal motivation of this research is the observable climatic changes that threaten human comfort in his environment consequent upon human attitudes to nature. Obviously, these changes militate against human environmental sustainability and development. However, importing the Risk Society Theory of Ulrich Beck as well as the Ecological Modernisation Theory of Arthur J.P Mol as effective tools, this present research intends to establish that there is the possibility of a formidable coexistence as well as a reconciliatory boundary between nature and culture in the cause of human development, in order to control environmental exploitations and so, reduce the damaging effects of natural hazards on human environment.

\subsection{Objective of the Study}

This research work tries to generate a re-orientation platform on the ideological framework on how humans should relate with nature in all their developmental plans, as a panacea to environmental exploitations and consequent avoidable hazards.

\section{Methodology}

The study used a qualitative design. The methods used were historical, descriptive, and critical. The historical method was used to trace the submissions of varied literatures on nature-culture relationships. The descriptive method was used to dissect the various anchors of the subject matter in order to understand in details the texture of its content as regards nature and culture. Finally, the critical method was used to weigh the various theories on the subject matter in an environmental scale, in order to assess their relevance in assisting humans in the management of their immediate environment, and in the overall development of their society.

\section{Results and Discussions}

\subsection{Nature-Culture Interpol}

Nature refers to all living and non-living things in the universe as well as the ecosystems. Often times, "nature" is misconstrued to mean "environment." In short, there is a tendency in the latter days, to render the term "environment" absolute, perhaps because of the increasingly widespread interest in the future of our world and habitat. But what exactly is the "environment?" Is it the same thing as "nature," or what the believer would call "creation?" By environment we anthropocentrically refer to the human environment otherwise called human culture. Essentially this means that the environment is that part of nature which is relevant to man and can be useful to him. Culture as used here therefore is the technological creations which humans design from nature for human development otherwise called the technosphere. On the other hand, by nature, one understands that every form of life is unique and therefore deserving of respect, regardless of its usefulness to man. This is what is often referred to as the biosphere. Nature is a subject in its own right, while the environment has a meaning only in so far as it is the part of nature which is useful to man. It is probably a consequence of the desacralization of nature that led to the appropriation of nature as a human environment which in its turn, led to the destruction of nature because it is much more than simply the setting for mankind. In the words of JurgenMoltmann,

Man, in fact, appeared relatively late in the evolutionary history of the Earth, indeed, by comparison with other creatures we are newcomers. In view of these considerations, it would seem that the term environment already expresses an aggressive attitude to nature, so much so that many of our problems derive from this anthropocentric egoistic way of considering nature which expresses itself in terms of lack of our respect for our fellow-creatures (Moltmann, 1991).

This aggressive attitude to nature'underlies the so many anthropocentric theories behind human cultural superimpositions. Some of those theories came from some grand anthropocentrists which we deem fit to consider here briefly: Thomas Aquinas, in his The Summa Contra Gentiles, developed the ethical implications of the great chain of being. In the great chain of being according to him, humans are closest to the likeness of God. Rational creatures exercise free will (that is, have dominion over their actions). God bestows on such creatures (namely, human beings) intrinsic value. "The actions of other organisms are causally determined by the environment, 
making them slaves to their surroundings. Because beings higher in the hierarchy manifest more fully the work and glory of God than beings lower down, and humans are at the top of the natural order, human beings alone are morally considerable. Moreover, human beings have the right to subjugate beings below."(Thomas,n.d.) Animals, for him, do not exercise free will and as such can be used and killed for human ends in accordance with the will of God. Anticipating Kant, Aquinas argued that the only danger in killing dumb animals is that such behavior might lead to cruelty to other human beings. This kind of conception must have spanked the conclusions among many that nature is not an end in itself, but instrumentally made for the realization of human ends.

On the same page with Aquinas, Rene Descartes in the Discourse, and in personal correspondence argues that either nonhuman animals are utterly devoid of sentience or they have human-like sentience; nonhuman animals he avers, do not have human-like sentience; therefore nonhuman animals are utterly devoid of sentience. He concluded that, "Nonhuman animals are, in a word, machines - albeit incredibly complex biological machines, the handiwork of God, but machines nonetheless. If nonhuman organisms are mere machines, then they cannot be the object of moral consideration any more than can a clock or an engine." ("Discourse on the Method Part V" and "Correspondence", 1985). Furthermore, Immanuel Kant, in line with his predecessors, maintains that "humans have no direct duties to nonhumans. Only rational beings are worthy of moral considerability (ratiocentrism), and only human beings are rational" (Kant, 1985). He agreed with Descartes that humans have no direct moral duties to nonhuman animals. For Kant, therefore, the class of beings worthy of moral consideration is coextensive with the class of moral agents -what he calls, "the Kingdom of Ends." These submissions among others are in no doubt, the roots of all the cases of destruction of nature by humans.

Conversely, a good number of nonanthropocentrists came up with their theories too in defense of nature. In their stride, they opine that nature should be respected in such a way that moral considerability should be stretched to it. For them, moral considerability should not be a strict reserve for only humans; it should be stretched beyond humans to other biotic and abiotic components of nature because they have autonomous intrinsic value in themselves and as such assume objective existence. Hence, to see nature as mere instruments to serve human needs is for them, the cardinal offence of anthropocentrism. Let us consider few of these opponents of anthropocentrism.

In his writing, Henry David Thoreau began by questioning the ontological divide between culture and nature. In his "Walking," he regards humans "as an inhabitant, or part and parcel of Nature, rather than a member of society."For him, "life consists with wilderness. The most alive is the wildest. Not yet subdued to man, its presence refreshes him." (Adams, 1938) This movement opens the invaluable page of nature, and sees man as part and parcel of it. If we are to give a deeper thought to Thoreau's position, we must come out with a conclusion that humans destroy themselves in their bid to destroy nature. This is because nature is an extension of human existence. Another clarion call for the revaluation of nature is that of John Muir. In the selection from "The Wild Parks and Forest Reservations of the West," Muir argues that "we need unspoiled wilderness as a sanctuary from the neuroses of modern industrial civilization."(Muir, 1901)Uplifting the face of nature by seeing it as a 'home' for humans, he surmised:

The tendency nowadays to wander in wildernesses is delightful to see. Thousands of tired nerve-shaken, over-civilized people are beginning to find out that going to the mountains is going home; that wilderness is a necessity; and that mountain parks and reservations are useful not only as fountains of timber and irrigating rivers, but as fountains of life. Awakening from the stupefying effects of the vice of over-industry and the deadly apathy of luxury, they are trying as best they can to mix and enrich their own little ongoings with those of Nature, and to get rid of rust and disease (Muir, ibid).

Furthermore, in his book, A Sand County Almanac the American philosopher, Aldo Leopold, introduced the concept of land ethic. By "land," Leopold refers to the entire ecological community of a place or of natural settings in general. In support of a land ethic, he says: "that land is a community is the basic concept of ecology, but that land is to be loved and respected is an extension of ethics." He continued: "A thing is right when it tends to preserve the integrity, stability, and beauty of the biotic community. It is wrong when it tends otherwise"(Leopold, 1949). Leopold took the concept of moral extension a step further by proposing a holistic 'land ethic' whereby value was attributed to the whole integrated biosphere of landscapes and ecosystems, rather than merely to individual life forms. He argued that throughout history, women and slaves were considered property, and so was land; and that now that we have (by employing ethical tools) granted rights and freedom to such individuals, it was unjust to continue viewing land in the same old way. He then pointed out that ethics should be extended to the land and that his proposition was both "an evolutionary possibility and an ecological necessity "(Leopold, ibid).

Moved by the preceding submissions, the Norwegian philosopher, Arne Naess, coined the term, The Shallow and The Deep Ecology. For him, the shallow ecology movement has just two objectives namely, combating pollution 
and combating depletion of natural resources. The objectives are isolated from the broader problems concerning ways of life, economic systems, power and structures and the differences between and inside nations. The deep ecology movement on the other hand has the two key objectives of the shallow movement, but uses them in a wide and deeper frame. The realization of these implies a change in the concept of life amongst the majority groups of the world's population. Such a change cannot materialize, he maintains, without reforms that will have consequences for all aspects of human life. In short, he avers strongly that "the equal right to live and blossom is and intuitively clear and obvious value axiom" (Naess, 1973). This change in the concept of life is a step towards the reconciliatory boundary which the American philosopher Rolston Holmes 111 strongly opted for in his "intrinsic value" theory. As the most well-known proponent of the autonomous, objective intrinsic value of nonhuman nature, a progressivist that hankers after holism - the moral worth of and interconnectedness of all elements (both living and non-living) in nature, Rolston insisted that humans should realize that various species in nature have silent activities that operate in them without any human assistance. They are the objective values in species that not only defy the instrumental concept of nature, but do not even need external valuers to be. Therefore, he argues that nonhuman biota are worthy of direct moral consideration. To cap it all, he maintained that individual organisms, as teleological centres of life, posses "autonomous intrinsic value" (Rolston, 1988) (that is, they are objectively valuable in and of themselves autonomously, or independently, of being valued subjectively).

These anthropocentric and nonanthropocentric opinions about nature are the underlying elements in the plurality of Nature-Culture Interpol. If humans are to move from nature to culture under the anthropocentric robe, the unguarded destruction of nature is imminent. This is because, for them, nature would not be seen beyond a mere instrument to serve human ends and as such would be exploited as much as it would fulfill a desired purpose. On the other hand, if humans are to move from nature to culture under the guidance of the nonanthropocentric concepts, nature would be tendered and guarded carefully with the concern that apart from its autonomous intrinsic values, it is part and parcel of man. Therefore, the inference could be drawn that however nature is handled in our clime is the after effects resonating from the bi-directional concepts of the anthropocentrists and the nonanthropocentrists. If nature is carelessly destroyed, the former is responsible; but, if carefully tendered, then it is consequent upon the latter. Therefore, if we are to strike an interactive balance between nature and culture in human developmental exploits, it is imperative to adopt the nonanthropocentric theories as platforms for sustainable environmental protection and management. The lop-sided nature of anthropocentrism will not install the homeostasis needed for environmental development, protection and sustainability.

In his Risk Society Theory, Ulrich Beck already points out this lop-sided nature in human developmental exploits. Referring to our present era as a phase of reflexive modernity, he theorizes that even though the development of science and technology, together with increased economic growth have helped to reduce material scarcity and increase the growth of living standards, there has been the creation of new problems and risks as a result of these developments. These problems arise because the human activities associated with them give rise to environmental problems. Examples of such risks are nuclear accidents and contamination, toxins in the environment, pollution and environmental degradation. Philip Sutton "believes that Beck's theory is helpful in highlighting the often hidden consequences of economic growth and consumption, along with scientific and technological developments" (Haralamboset al., 2012). Those consequences, it would appear, are no longer hidden because they are all evident in our contemporary environment.

\subsection{Humans: The Agents of Balance between Nature and Culture}

RolstonHolmesnoted that "Humans are a paradox on Earth, both a part of nature and apart from nature." (Rolston III, 2012) This paradox accrues from the fact that even though contemporary biology teaches us that we humans are part of nature, humans are also apart from nature because we are by nature Aristotle's "political animals" and have made an exodus from nature. The major philosophical challenge here is that humans need a sense of place, a kind of independence from nature, a kind of technosphere; yet, this must happen within a biosphere. Putting it right, Rolston said,

Humans evolved out of nature; but, in important senses, they did just that, they evolved into culture, contrasted with nature. Humans nurtured into an inherited culture. This cultural genius makes possible the deliberate and cumulative, and therefore the extensive, technological, rebuilding of nature. ...but nature, we have discovered, remains the milieu of culture...nature is the womb of culture, but a womb that humans never entirely leave (Michael, 2001).

In other words, no matter how dense the claims of humans are as apart from nature, the claims still hold against him especially in the evident human dependence on nature for survival or even for man's culture. As heterotrophs, humans are inevitably part of nature because of their dependence on nature for air, water, sunshine, food etc. As 
autotrophs for instance, plants produce their food by a direct contact with the sun, and humans depend on plants for the produced food if they must survive. Hence, ecology still lies in the background of culture, natural givens that underlie everything else.

Nevertheless, as the most sophisticated natural products, humans are by virtue of their endowments, set apart from nature. As a Homo sapiens, it is observed that although humans evolved from other primates, the human brain is not just a scaled up version of a chimpanzee brain. Humans are remarkable in their capacities to process thoughts, ideas, symbolic abstractions figured into interpretive gestalts with which the world is understood and life is oriented. Michael Merzenich, a neuroscientist, reports his increasing appreciation of "what is the most remarkable quality of our brain: its capacity to develop and to specialize its own processing machinery, to shape its own abilities and to enable, through hard brainwork, its own achievements" (Kagan, 1998). Notably, these endowments make humans moral agents. The uniquely rational animal is equally the uniquely ethical animal. Ethics is distinctively a product of the human genius, a phenomenon in our social behavior. To be ethical is to reflect on considered principles of right and wrong and to act accordingly in the face of temptation. In the words of Jerome Kagan, "What is biologically special about our species is a constant attention to what is good and beautiful and a dislike of all that is bad and ugly. These biologically prepared biases render the human experience incommensurable with that of any other species" (Mol, 2010). There is so to say, a mental distance between humans and other species in nature. Invariably, humans are the moral agents in whose hands, the interactive balance between nature and culture, the reconciliatory boundary between nature and culture, as well as the sustainable environmental protection and management reside. In other words, though apart from nature (by his endowments), man is still part of nature (by his evolutionary history), and as such should take care of nature.

Man, taken from its etymological nuance (anthropos in Greek), means to rise up, or to look up. The duty of man in nature therefore, is to rise up from the earth and look over their world. In the excellences of man, he excels in the capacity for overview. The novelty in the human emergence is class altruism emerging to coexist with class self-interest, sentiments directed not simply at one's own species but at other species fitted into biological communities. Humans ought to think of earth as an evolutionary ecosystem out of which they have evolved, which continues and remains as their life support, and which they ought appropriately to respect. To realize this, humans should be liberated out of egoism, out of humanism, into a transcending overview that sees nature as blessed, exuberant with life, full of integrity, beauty, dynamic achievement, and storied history. It is only when nature is conceived thus that humans can be genuine altruists, recognizing the claims of other humans and the claims of nonhumans as well. By the spank of this altruism shall all the developmental projects be subjected to, and pass through environmental protection and sustainability censorship and tests.

In addition to the aforementioned 'ideological' liberation, there is need for concrete proactive moves for environmental protection and sustainability. A good way of starting this movement is by adopting the tenets of the Theory of Ecological Modernization as proposed by Arthur P.J. Mol and GertSpaargaren. They see the notion of Ecological Modernization "as the social scientific interpretation of environmental reform processes and practices at multiple scales" (Mol, 2010). These processes and practices are the ecology-inspired and environment-induced transformation and reform in the central institutions of a modern society where science and technology are no longer analysed and judged only as the causes of, but also as the solution to environmental problems (Nagel, Dietz, $\&$ Broadbent, 2008). Science and technology will now be conceptualised and valued from the point of view of their potential role in: bringing about environmental reforms; the prevention of environmental crises; using sociotechnological approaches, through the incorporation of environmental considerations at the design stage of technological and organisational innovation, and by making environmental and institutional arrangements in the process of environmental reform. These arrangements would also imply the proactive involvement of economic and political institutions, as well as of social movements and intergenerational solidarities in this environmental reform process. This whole picture is reflective of the concept of the 'technological fix '(De Souza, Williams, \& Meyerson, 2003) and of the human 'creative capacity'(Nnia, 2017) which are believed to possess the potentials of resolving extant as well as emergent environmental problems.

\section{Summary and Recommendations}

Moral philosophy in the Western World centred more on human beings than the human environment. This was refused the widest acceptance with time, giving rise to environmental ethics borne with a concern on how humans, as moral agents, should best live their lives in their common home. If man is to value nature objectively, with due respect to the intrinsic values in nature that aid human existence by the ecosystemic connectivity and relationality, man will not only escape much sufferings from environmental hazards, but will also enjoy a harnessed environment for sustainable development. It is this sustainable development that will not only guarantee a 
comfortable existence to this generation, but even to future generations after us. Otherwise, what NniaNwodo foresees that "in the years ahead, we could face very severe ecological challenges that will impact negatively on our economy" ${ }^{23}$ may not be far from the truth. The anthropocentric moves, in its lop-sided regalia would hasten the destruction of nature unlike the nonanthropocentric moves that would uphold and protect nature. Therefore, to realize nature-culture Interpol, humans should be guided by the latter's tenets; otherwise, destruction of human environment by natural hazards is inevitable.

To forestall the interactive balance between nature and culture, this research work recommends inter alia, that all developmental projects must be subjected to, and pass through environmental protection and sustainability censorship and tests. This requires that an 'Environmental Censorship Body' should be formed in Communities, Local Government Areas, States, Federations, and on International levels. It should be the mandate of these bodies to liaise with individuals who plan to move from nature to culture in their developmental plans. By this action, unguarded exploitation and undue destruction of nature would be highly moderated, giving rise to a reasonable and reconciliatory boundary between nature and culture for a sound ecological homeostasis.

\section{Conclusion}

Humans, at the center of nature should not destroy but preserve it. The method of that preservation is that man should appreciate the inherent activities in other species within the ecosystem. This will reduce unguarded exploitations of nature, and make for a progressive interconnectivity and interdependence between man and the rest of ecosystemic community. If man becomes conscious of the intrinsic value in species as prominently held by the nonanthropocentrists, human health and sustainable developments will be realized; otherwise, natural and human disasters may take less time to overcome man with an irredeemable destruction. Meanwhile, environmental reports show that we shall soon be out of things to exploit, except the very last dregs, and the most toxic and poisonous things of all. The oceans are full of plastic and the skies full of carbon. The only thing left to exploit is each other. Henceforth, google search is unnecessary in finding the cause of man's inhumanity to man that is replete in the modern times. Immanuel Kant warned against cruelty to animals which he foresaw as what would degenerate to cruelty to fellow humans. Once humans alienate from their environment and take to its exploitation, they must face each other for the same exploitation if what to exploit in the environment is exhausted. Among other recommendations however, environmental censorship and tests as recommended in this research would offer a reasonable solution that will enhance an interactive balance between nature and culture for a sustainable environmental protection and management.

\section{Competing Interests Statement}

The authors declare that there are no competing or potential conflicts of interest.

\section{References}

"Discourse on the Method Part V" and "Correspondence". (1985). In John, C., Robert, S., \&Dugald, M., (Eds. and Trans.),The Philosophical Writings of Descartes(vol. 1, 302-304). Cambridge: Cambridge University Press.

Adams, R. (1938). THE WORKS OF THOREAU, edited by HS Canby (Book Review). New England Quarterly, $11(1), 642$.

Blasi, P., \&Zamagni, S. (Eds.). (1991). Man-environment and Development: Towards a Global Approach: Nova SpesIVth Nobel Prizewinners Meeting. Nova Spes.

De Souza, R. M., Williams, J. S., \& Meyerson, F. A. B. (2003).Critical links: Population, health, and the environment (Vol. 58, No. 3). Washington, DC: Population Reference Bureau.

Francis, P. (2015). Laudatosi: On care for our common home. Our Sunday Visitor.

Haralambos et al. (2013). Sociology, Themes and Perspectives (p. 999). London: HaperCollins.

Holmes Rolston 111. (2012). A New Environmental Ethics: The Next Millennium for Life on Earth (p. 52). New York: Routledge.

Kagan, J. (1998). Three seductive ideas. Harvard University Press.Cambridge. MA: Harvard University Press.

Kant, I. (1985). Grounding for the Metaphysics of Morals (2nd ed., pp. 39-40.). Indianapolis, IN: Hackett Publishing Company.

Leopold, A. (1949). A Sand County almanac (pp. 237-239).New York: Random House.

Michael, M. (2001). The Power of Mutable Maps. In, Mark Bear et al., Neuroscience: Exploring the Brain (Baltimore: Lippincott Williams and Wilkins, 2001), 148.Jones \& Bartlett Learning, LLC. 
Mol, A. P. (2010). Ecological modernization as a social theory of environmental reform. The international handbook of environmental sociology, 63-76.

Moltmann, J. (1991). "Environment Versus Nature" In Blasi, P., \&Zamagni, S. (Eds.), Man-environment and Development: Towards a Global Approach: Nova SpesIVth Nobel Prizewinners Meeting (pp. 85-86). Nova Spes.

Muir, J. (1901). Our national parks (Vol. 16019). Houghton, Mifflin.https://doi.org/10.5962/bhl.title.53718

Naess, A. (1973). The shallow and the deep, long-range ecology movement.A summary. Inquiry, 16(1-4), 95-100. https://doi.org/10.1080/00201747308601682

Nagel, J., Dietz, T., \& Broadbent, J. (2008, May). Sociological perspectives on global climate change. In Workshop report from workshop held May.

Nnia, N. (2017). 50 Years After Biafra: Reflections and Hopes. A paper presented at the Yar'Adua Centre on 50 Years of Biafra in 2017.

Rolston III, H. (2012). A new environmental ethics: the next millennium for life on earth. Routledge.

Rolston, H. (1988). Environmental ethics: duties to and values in the natural world: book summary.

Thomas, A. (n.d.). Summa Contra Gentiles, Part 11 Bk III (c. 112, [1]).

\section{Copyrights}

Copyright for this article is retained by the author(s), with first publication rights granted to the journal.

This is an open-access article distributed under the terms and conditions of the Creative Commons Attribution license (http://creativecommons.org/licenses/by/4.0/). 